\title{
Travelling feelings: Narratives of sustaining love in two case studies with fathers during family separations
}

\section{Alexandra Macht}

Oxford Brookes University

amacht@brookes.ac.uk

Author Biography:

I'm a lecturer in Sociology at Oxford Brookes University, UK. I gained a PhD in Sociology from the University of Edinburgh in 2017. I co-edit the annual review of The International Network of Leave Policies and Research, alongside Peter Moss, Sonja Blum and Alison Koslowski. My first book Fatherhood and Love' is will appear in 2019 with Palgrave Macmillan.

\begin{abstract}
:
David Morgan' (2011) influential concept of 'doing family' not only 'having a family', has yet to be applied to the emotional dynamics inherent in the cultural shaping of fatherhood. Drawing from two case studies, of a Scottish and a Romanian father, I reflect in this chapter on the interconnections between 'doing family' and 'loving', as types of relational and emotional activities which maintain family bonds across borders despite intimate separations (divorce) and work migration. These case studies are taken from a qualitative research project exploring 47 fathers' experiences of involvement and love in their family lives. The specific case studies of Sergiu and Keith, marked by emotional trade-offs and relational give-and-takes in different spaces, illuminate the contradictions of their involvement in their close relationships to their children and expartners. For these two fathers, the process of 'doing family' after separations was a disjointed and renegotiated one, involving the use of emotional reflexivity, developed because of their changing lifecircumstances. In this process, both fathers recount how they began reconfiguring their masculine identity from providing to establishing intimate fathering (Dermott, 2008). These changes occurred when their normative precepts of family life were transformed in situations of emotional upheaval, movement and relocation. As their families were in motion, fathers mentioned instances of changing their communication strategies to express love in more visible ways to their children, directly constructing their 'good fathering' identity (Henwood and Procter, 2003) from renewed positions. Family separations in this context offered the potential to challenge the traditional father's role.
\end{abstract}

\section{KEYWORDS:}

1. Emotional reflexivity

2. Father(s)

3. Parental love

4. Travel

5. Separations

6. Scottish / Romanian

\section{Introduction}


Contemporary family relationships in Europe are undergoing dynamic changes, which can be unsettling but also creative. The increasing diversity of new family forms require social actors to undertake flexible family arrangements in the wake of global changes (such as, commuting for work or study, divorce and recoupling, or migration). These social changes influence how family members reflect on their emotions and gender roles. Driven by emotions, new intimate spaces are created that challenge normative notions that portray family life as static, culturally homogenous and undifferentiated.

It is important to clarify from the beginning that - different from the psychological concept of 'attachment' (Bowlby, 1969) constructed in relation to the important role of the mother as the primary caregiver in a child's life - 'love' in this research is used to make visible everyday narratives of two fathers' affection.

A body of previous work emphasized the dynamic aspects inherent in the doing of emotion (Scheer, 2013), the doing of family (Morgan, 2011) and the doing of gender (West and Zimmerman, 2000). In this chapter, I explore through two case studies, how the three abstract theoretical concepts can be utilised to make sense of the personal experiences of two European fathers from different cultural backgrounds.

Scottish and Romanian fathers are usually considered as representative of Western- and EasternEuropean fathering identities. However, this facile dichotomy takes place because we know little of the everyday complexities of living intimately within these two cultures. This is because accounts from Scottish and Romanian populations on emotions are under-represented in the literature on fatherhood and on men and masculinities.

The aims of the research were: a) to include fathers into the general discourse of love (mostly dominated by accounts of romantic love), b) to represent parental love, c) to shift the focus away from essentializing and over-burdening the mother's role, and d) to reveal emotional potentialities to further gender-based social changes (hooks, 2004). Exploring love in the context of fatherhood is important since father's relationship with the child although embodied, is removed from essentialist considerations of the body (usually reducing it to its biology).

The case studies I discuss in this chapter are taken from a larger research project which explored the emotional experiences of 47 fathers from two cultures. I purposefully selected a group of involved fathers with various characteristics not only cultural differences (such as middle-class and working-class, resident and non-resident, separated or married, young and old) to understand what I assumed were different ways of experiencing love in intimate relationships. This is because both fathering and love are culturally and socially-dependent experiences (Padilla et al., 2007). The qualitative findings of my research, anchored in a grounded methodology (Charmaz, 2014), mainly revealed that fathers understand love as something that they $d o$.

This meant that the everyday practice of involved fathering required their active participation in the doing of their family. It also necessitated emotion work in challenging traditional understandings of fathering as providing, mainly reliant on time away from home to work and emotional control and stoicism. Therefore, emotions matter in an analysis of fatherhood, as they represent core aspects of how gendered relationships are lived (Hochschild and Machung, 1990). Both affective practice and social practice feed into social actors' personal biographies. Or to put it differently, to be an emotionally involved father and to engage in intimate fathering, one has to feel like a father and relate to family members from this position.

The dynamic nature of their changing work and family situation - for these two separated, nonresident and commuting Romanian and Scottish fathers - illuminates the processual aspect of how feelings travel across distances, how they serve to maintain close family bonds despite physical and geographical separations, and how expectations of good and intimate fathering travel across the 
European cultural space. The dissolution of romantic love is not simply an unfortunate event, but it can also bring into the foreground the practice of parental love. Even if family separations caused by divorce are stressful life events, they can also have positive outcomes, as they can contribute to father's increased emotional reflexivity. This in turn, helps fathers shift from the provider, or the traditional role of fathering, to progressive models of intimate fathering and caring masculinity (Elliott, 2015).

\section{Methodology}

Emotions as social relations, a complex consisting of imagination, memory, embodiment, reasoning, feeling and power (Burkitt, 2014). The premise of emotional bordering a term I created based on the grounded data is that as men reconcile their masculinity with their fathering role, they shift emotionally from intimate fathering to stoic providing from love to detachment (and vice-versa) according to social context and type of relationship. The study is a qualitative investigation of how involved urban fathers understand love in their close relationships, comprising of: 47 interviews (20 in Romania, 27 in Scotland; 12 working-class men, 35 middle-class men) and 6 observations (3 at home, 3 at work). The method and analysis were informed by grounded theory methodology (Charmaz, 2014).

\section{Doing family and emotional reflexivity}

The focus on doing across all the areas mentioned points towards the embodiment of action, and of considering love, family and intimacy as practices, as forms of activity detached from mere being. But what precludes action, are moments of deep reflection, or of employing emotional reflexivity.

According to Mary Holmes (2010) emotional reflexivity is “(...) an emotional, embodied, and cognitive process in which social actors have feelings about and try to understand and alter their lives in relation to their social and natural environment to others" (p.140). Emotional reflexivity is thus a reliance upon emotions to decide how to act in the social world and how these interact in reproducing social actor's intimate lives. However, as the case studies show, this reflexivity is not used uniformly in maintaining family relationships.

For example, fathers prioritized the love of their children over the fragmented relationship with their ex-partner and described separations as marked by resentment in one case, and by regret in the other. Reflecting on these complex feelings offered fathers the ability to name them and decide how to act in new ways, or put differently to father differently and love visibly, as part of the process of assuming a new identity, intimate fathering. Both Sergiu and Keith discuss below how even if inspired by slightly different relational circumstance they shifted from the stoicism of the provider's role, to the intimacy of the emotionally involved father's role.

In the formation of close intimate relationships three interlocking processes take place: a) constructing a masculine identity, b) embodying the father's role and feeling, and c) expressing these feelings. Such are the constantly moving dimensions embedded within the process of relating and feeling. It is the configuration of these processes that adds mobility and dynamism to personal lives. In the two case studies, what links being and reflecting with doing, is the existence of travelling feelings produced through the movement of the separation and commuting for work which re-shapes who these two men think that they are as fathers.

Travelling feelings

What I mean by this term are feelings which are born in transit, a form of mobile emotions. Up until recently emotions have been considered as private, static, inward and biologically-determined entities (Turner and Strauss, 2004). However new social-constructionist thinking moves into explanations of emotions as existing in social relationships, as dynamically produced in the interactions between people, through language, memory, imagination and embodiment (Burkitt, 2014). This perspective can be applied to the case studies, as participants recounted in 2-hourslong interviews how they travelled between countries, immersing themselves in different cultures, 
and interacting with a variety of people in-between the two environments, which enhanced their emotional reflexivity.

This emotional shift in turn helped fathers reflect on the characteristics of the traditional breadwinner role that they incorporated in their fathering (strictness, offering material goods, discipline) and helped move them into the new intimate father identity (cooperative communication, caring and affectionate, positive interactions). Love in this understating is not a singular emotion but rather forms an emotional complex. According to Ian Burkitt (2014) emotions are complicated feelings but also form an embodied complex of feelings, functioning both at the level of practices and at the level of language. Thus, they can involve other emotions, such as worry, joy, and power. Ian Burkitt's aesthetic emotional framework (2014) applied in this research for the first time in relation to fathering and love, conceives of positive emotions (such as love) not as inherent, 'natural' entities, but as a socially-created ones, which can coexist in the same close relationship alongside another negative emotion (such as guilt or anger).

Seeing the social landscape through an aesthetic theory of emotion helps, as a way of interpreting men's emotionality, and consider the role of the father as a relational construction. This is because both 'fatherhood' and 'love' are dynamic social constructs. Across the two narratives, geographical differences expanded into emotional questions of how to maintain closeness across distance, and what it meant to remain a 'family' and a 'father' despite separations which occurred nationally and transnationally. Based on the research conducted by Lynn Jamieson (1999) and David Morgan (2011), we know that practices of intimacy and of 'doing' family involve connectedness and closeness. But my concerns in analysing the cases was to understand how is closeness maintained at the distance? How is parental love expressed when apart? I hope that the case studies presented in this chapter can partly illustrate these expansive questions.

\section{The case of Keith}

At the time of our interview, Keith a Scottish father from Glasgow, worked for a large corporation in Edinburgh. He has a 9-year-old son Terry and a 7-year-old daughter Miranda. He began the interview by sharing that he was in the process of divorcing from his wife, who had moved to England with the children to live in her parents' home. Keith was working in Edinburgh and commuted every weekend down South to be with his children. He shared with me that his work contract was to expire in the next month and he was preparing his relocation down South. His interview was filled with reflections on how this situation will change, now that he has decided to be around his children more because of the separation.

Keith, who proudly identified with his Glaswegian roots in the formation of his masculinity, began by describing how his parenting is different from his father. He added the he learned from his mother how to be a good parent:

I was brought up in Glasgow, in a relatively working-class environment. So, I was the child of the $60 \mathrm{~s}$ and the 70 s so very different, I mean parents were less engaged (...) where I was brought up we went out and we played out all day. We came home. So, there was less engagement with your parents now it's much more...kids don't get that kind of freedom, so there's more pressure on the parents to perform more roles (...) I think to some extent a lot of what I've been trying to do is maybe give the kids the childhood that I didn't have, or certainly that's the influence. Well my father was ever-present but he I don't feel that he saw fathering as his job. He just expected us all to grow up. So, he was the provider: he went out and he worked and then weekends he spent gambling. Yeah that was his preference, he preferred to be gambling than to be spending time with the kids and then we did whatever we did. But that wasn't uncommon 
in those days (...) I mean, he cared for us, but it was in a detached way and my mother was trying to hold it all together and she was very loving. (...)

Contradictorily he described his relationship with his wife on rather negative terms, all while emphasizing her important role as a mother:

If I look back I'd definitely would have benefited from being told that she was proud of me and that I'd done well. So I think to a certain extent, one thing I'm learning as I get older is that these are things that you need to do for yourself. In my head the role of the father and the mother [are different], and primarily the mother is nurturing and protective, and the father is to prepare the children for adulthood and for the future. In the situation were you're not comfortable that your wife's fulfilling that role then you tend to stray into that world [of nurturance]. I'm probably more nurturing as a father than I would be if I felt that that [they were] being handled better by the mother, as an example.

During the interview he mostly described the different approaches to parenting that he and his wife adopt, and often shared that he struggled to understand why according to him, his wife finds it difficult to enjoy motherhood and be nurturing:

I mean ultimately, I just want the best for my kids, and on an abstract level my wife does as well. She just didn't get that bonding thing it just didn't happen and that's sad (...) The thing is I really enjoy their company. I mean I think that's the big difference between me and my wife (...) It's not like she doesn't love them. She does love them, but she's on edge in their company, and she sees them as work. She doesn't relax and she doesn't enjoy them. Then of course that has a knock-off effect with them, because they don't feel appreciated.

Paradoxically, this difficult situation for his family members, shrouded in resentment in his narrative, pushed him into the realization that his role as an intimate father was expected. Because his ex-partner dealt with recovering from the divorce and a subsequent disease, Keith was in the process of coming to terms with this realization and discovered that he had to fulfil the role of the nurturing and emotionally available parent:

I mean I'm very affectionate with my children, so there's lots of hugging and throwing about and chasing them about (...) so the next phase is to move down there and then it might get a little bit more challenging in terms of I'll be commuting and then coming back, maybe it wouldn't just be as special, but I don't think it will, I think it will stay like this because. Ultimately I don't want to live through my children, but how I see it is this: at the moment in this point of their lives I'm providing for them not only love and stability but also the idea that the world can be different and exciting, and that's an incredible privilege to have that for two people you love and so certainly while they are at this stage and for as long as they need that, that's how I want to be spending my time, not sure what happens if they turn into monsters when they become teenagers! But personally, I doubt that. They're never far from my thoughts.

In the above quotes, Keith emphasizes the relational character of his fathering identity and how this changes as his close relationships change. In the below paragraph, he describes how an emotional awareness (or emotional reflexivity) helps him maintain intimacy with his children despite distance and the family separation:

I suppose what influences your love is your level of awareness and understanding (...) I'm very understanding with my kids. So I can see when they misbehave I'm 
always looking for where that's coming from rather than just taking it at face value. In other words, for example "Why is Alex being unpleasant to his sister? It's because he's jealous, because he wants all my attention". Just trying to get that across without making him wrong but at the same time making it clear that it's not acceptable so that's the first thing is your level of awareness. In terms of expressing love it depends what love means. In the sense that what you want is the best for your children, then the way to express love is to encourage them; to encourage good behaviours and to discourage bad behaviours.

The contradiction inherent in his narrative was that despite describing himself as a caring and loving father, he does admit that he spends little time in presence of his children, which is usually concentrated at the weekends as he had to commute for work during the week. He also admitted that his commute puts him in the privileged position of sharing with his children only the best emotional moments, mostly the positive ones:

When I go down [to the South] I'm going down to see them. So, I'm tired, I might get back at $10 \mathrm{pm}$. I might be knackered and a bit irritable, but it might just be "Look I just need some space!" That's kind of how it'd probably go. So, it's a very different dynamic, then if you're coming home every night. In some ways I think it's made it a lot more special (...) So Saturday mornings get taken up with football, I'm taking Alex to football and then Saturday afternoon typically go swimming or go and see a film, you know get something to eat and then in the evening we'll watch some nonsense on television, that they like and then we'll all cuddle up and have a laugh and then that's our Saturday, but it's lovely.

He admitted to keeping any disciplining or arguments in check because he only sees his children for short-times the aim is to enjoy their company. Again love was described as a relationship, enhanced by everyday simple activities, and activity as deeply connected to his masculinity:

Well I'm really looking forward to spending more time with them, and just doing the simple things which I don't get to do with them like doing homework with them, teaching my son I don't know whatever it is, use Ebay. You know just the simple skills, cooking with them and trying to prepare them and get them to understand how things work and having fun with them. But a lot of it is just about the mundane, isn't it? It's enjoying the mundane rather, than everything having to be special. At the moment there's a lot of pressure every weekend I go down. So, I want to move away from that, for it just to be what we're doing. Like making the time to sit there or teaching them how to clean their shoes. Love is in simple things (...) I also think that - I definitely see it with my son, probably less with my daughter - he's watching me all the time trying to figure out how to be man, you know that's what they're looking for.

Despite being nurturing to his children, Keith's interview is replete with differences in how he describes his relationship to his son (considered more intimate) than with his daughter (considered more distant). In the data excerpt below he denotes the significant use of emotional reflexivity in making sense of the insights he accrued through travelling:

I can say, I'm about to move and there are times when I'm kind of overwhelmed with anxiety (...) When you're in that kind of space you're not always as clear as you'd like to be (...) it's a very unusual setup, it's incredibly intense. I go down into the home environment and with the kids for two days, but then I get to come here and process it all. So that's giving me a lot of clarity about what's important to me and how important my kids are to me (...) Like with anything I think the 
biggest challenge in the dynamic of the three of us, in that my son can be unpleasant to my daughter, especially when he's feeling jealous and I think it's heightened when I'm there (...) I love it that they're both connected to me and want to be with me, and I suppose that's just because like I said, how I feel about them is very uncontaminated and clear; they know I love them and I'm not trying to get them to do things that they don't want to do unless it's if they eat vegetables.

In summary, Keith seems to enjoy the prospect of moving down South and 'stabilising' his family following the separation from his wife. He speaks fondly of wanting to be closer to his children, but his narrative also reveals a sense of anxiety about switching from providing to intimate fathering and enacting this new identity in his everyday relationships with his children. He is able as well to reflect on the resentment that was produced in the dissolution of the romantic love for his ex-partner, all while describing the strengthening of the love he feels for his children. Lastly, it is noticeable from his narrative how adopting this new role of intimate fathering is emotionallymediated and determined by the changes in his wife's and his children's relationships to. As such, it is not simply an individual, autonomous and rational choice, but a relationally-contingent one (Burkitt, 2014).

\section{The case of Sergiu}

Sergiu is a Romanian father of two, who arrived in Scotland for work, a couple of months prior to our interview. He went through a divorce last year, which saw his ex-wife Clara, relocating his two children 15-year-old Matei and 11-year-old Anca, to a Southern European country. Before arriving to Scotland, Sergiu worked as an accountant. Because money was tight, he began travelling to the UK several times since 2001 to work in constructions and improve the family's financial situation. Sergiu however was demoralized because he interpreted his efforts to create more wealth for his family as a marker of the separation. He now commutes between Romania and Scotland for work, while the other members of his family reside in the South of Europe. Only the children's two grandmothers (his mother and his ex-wife's mother) remain in Romania. According to Sergiu, he sees his children once or twice per year because commuting is expensive. At the time of the interview he was 2 months away from his next visit to Bacău, his native city in Romania, where he was to re-join his children to visit their grandmothers.

Much like Keith, when asked about his fathering role. Sergiu begun to describe his own upbringing. He mentioned growing up in his uncle's adoptive family, where his educational achievements were equated with displays of love:

They [adoptive parents] didn't use to express it [love]. Only when I was tiny I think. They used to show love when there was an achievement, there used to be lots of praise if you won something [at school]. "Oh, you've done this, you are such a clever boy”. But aside from that I didn't see it.

He continues to describe his own fathering by contrasting it to his relationship with his father figure (his uncle) and how he is trying in the present to be more sociable than him in his new intimate role. He explains how he was brought up to adopt a traditional masculine role, within which he felt he had to be emotionally stoic to be a 'real man', and this then translated into his type of fathering, that became disciplinarian:

[I was] very strict. I don't know, I tried to raise them through education. I mean I see parents who allow their children to do whatever they want, but I used to tell them - perhaps far too many times - "Do this, do that". When I saw that they wouldn't do it, I would get angry and when I got angry I would scream. I used to 
get very cross. I've been reprimanded, but that's the way it is, I'm just that kind of person.

He carried this pattern into his own fathering, for example by associating money with his children's studying success, but also by keeping money in mind in their everyday activities:

We used to do the normal things as a family. I tried to help them with homework, we used to go out in the weekends for a barbecue, or in the park, we walked through malls. Every time we shopped for groceries there had to be some money left aside for them, because they would ask 'I want this and that game' (...) When I saw that they were not studying, I tried to explain that 'it's not good, and I started to give them money for every high mark, something around 10 to 15 lei. For a while this worked, but after that they got distracted by other things, and they stopped coming with the marks, so they didn't get any more money.

As part of his breadwinner identity, Sergiu explained his "love power" (Fergusson and Jonasdottir, 2014) as exerting control over children, following the traditional model in Weber's tripartite theory of power (1978). However exerting power in a loving relationship took for him the form of protection, even if unequally shown in connection to his daughter rather than his son:

(...) Yes, I was more protective with the girl, especially when she was smaller. I left the boy a bit free. But with my daughter, especially since she was at a school in the centre of Bacău, I didn't want to let her cross so many streets alone. My boy was in a school closer to home, so it wasn't that dangerous. It was also the thing that I left him to walk home alone, so he learned to come home earlier on his own. But as I said, he's a boy so he can handle himself on his own, even if nowadays he is reproaching me about it, but that's the way it is.

According to him, as a moral 'educator', Sergiu took control over his children's socializing practices when they were younger, by overseeing their homework and participation in formal education, denoting the inherently patriarchal quality of his previous role. His account also shows that perhaps processes of de-traditionalization might not be conducive to negative consequences in the wake of relational break-down, as Sergiu's power over his children was reduced in the wake of a divorce. He therefore learn to adapt his control and developed alternative and more affectionate ways to communicate with them, informed by his ex-partner's mothering, as he says:

Even if I am a man, I noticed what my wife was doing and followed her, so I managed [in fathering]

For example, in the paragraph below, he is comparing his emotional expressiveness with his exwife. By comparison he finds himself lacking in emotional skills because he explains that he felt that his role as a provider meant that he had to focus on money and material concerns:

I mean even if she shouted at us, she would start being affectionate again after half an hour and there would be kisses. I used to stay upset for longer 'I told you to do this and that!' and I stayed upset for longer, I couldn't revert that's just how I am. Other guys are probably not like me. I realize now that I can't love like a mother, but the fact that all this time I wanted to make more money so I can send them some. Even now I have to send them a third of my salary, so I constantly have to ask for over-time at work, so I can work more and give them

1 'Lei' (plural; singular: Leu) are the Romanian national currency; the sums mentioned are the equivalent of 1.50 to 3 pounds. 
more. I don't know if this means love, maybe it just means duty, but that's what I feel I should be doing because they are my children.

Furthermore, Sergiu described how initially he was proud that his first-born is a son. Having a son according to the traditional cultural expectations in Bacău, is assumed would make life easier and less worrisome for parents. Sons normally contribute financially earlier in the family and need less protection. However (and contrary to Keith), Sergiu realized that emotionally he felt closer to and bonded easier with his daughter. In his explanation he attributes this to the girl's birth order and not necessarily her gender. Sergiu thought that because he had already gained parenting experience, once his second child arrived, he found himself better able to express love:

The girl spent a lot more time with me when she was smaller. Whenever I used to hold my son he would sit there for a while but then struggled. He didn't really like to stay in my arms. He always wanted his mother so he can suckle. But my girl stayed, no problem. One time, my son had some minor health issue and he had to be hospitalized for a week. My wife stayed with him. So I stayed home and took care of my daughter: we travelled together by bus, I held her, she slept well at night, sometimes she would wake up and I would bottle-feed her, and thn she would fall asleep again. There were no issues. She bonded with me more and I also felt a lot of love for her.

Midway through his narrative, Sergiu revealed that he what prompted him to reflect and shift towards more intimacy was not simply the regret produced by the divorce, but also encountering a different culture to his own. Commuting for work to the UK, made him reassess whether raising children in a disciplined and emotionally controlled way is actually 'raising them well':

When I started seeing that parents here [in Scotland] allow their children to tumble down, have fits and roll on the ground, and the parent won't even budge, won't even say anything...I don't know, I mean I used to tell my own that this kind of thing is not civilized "Don't do this, be good". So yeah I'm not the type [...] I also think it had to do with how I was raised, badly, and without realising I gathered all these habits. I used to be told the same "Don't do this, don't do that", even if I wasn't a particularly badly behaved child. It was mostly at school that I would misbehave, rather than at home where I was kept under control.

As previous studies show, migrating from one culture to another can create shifts in how people relate to each other (Beck \& Beck-Gerhnsheim, 2014), and Sergiu's narrative reflects such changes. He now tries to educate himself to be a more emotionally open father, and rebuild his relationship with his adolescent children, by communicating daily with them and telling them he loves them. One strategy to establish closeness despite distance is trying got keep in touch with his children through social media:

I try very hard [to keep in touch] The boy is now very busy. He goes out a lot with his girlfriend and I can tell from what he posts up on Facebook what he's been up to. I think that they read my direct messages, but these come second. They prefer to post all sort of shenanigans on Facebook and think like "Aaa why is my dad messaging me?" I also try calling them [on the phone], because as I said they tend to ignore me on Facebook. So I call every day, but I usually talk to my girl as she's mostly at home, my boy is mostly out. I have to do it [call them] there's no other way, because if not, they ignore me and will forget about me.

Memory plays an important part in keeping his children from forgetting him but also in keeping their shared past experiences alive. Therefore, Sergiu relies on sharing memories through the telephone to maintain the emotional connection to his children. In this context feelings travel 
across both geographical and temporal distances in achieving intimate fathering. However, the positive memories include also negative emotional undertones as Sergiu feels as if his efforts to provide them with holidays, were not fully appreciated by them:

So, when I call home I usually find her [his daughter]. I usually don't reach the boy. I tell her more often that I love her and that it would be nice to do some of the good things we did as a family: to go to the seaside and back home [in Romania] I mean they also have the seaside in Portugal, but I would really like to go again to where we used to back in our country, at the beach, at the mountainside, in beautiful places. I try to get them to recollect a little bit "Do you remember when we used to go to the beach? Where was it better, here or back there?" But I recall they were also bored, they didn't understand, that it was what I had wanted to do for them, and with considerable effort from my part to get them there (...) When I arrived in the UK the first time and I started working, I tried every year to take them somewhere, but they started to seeing it as something commonplace. I noticed they didn't appreciate it that much, that I was doing an effort for them.

The main theme of his account is how money is becoming dissociated from love in his experience of moving away for work all while having to move on emotionally following the separation. In the absence of prior social models which could successfully teach him how to express his emotions without compromising his masculinity, he had no choice but to re-create his relationship to his children 'as he went along'. Aware of this intimate breakdown in the relationship with his wife, he employed emotional reflexivity and reorganized his priorities. Now he keeps in touch with his children who live abroad, through social media and by phoning them daily to tell them that he loves them, maintaining closeness even if at a distance:

I realize that they are distancing themselves from me, being away from me as they are. I'm really sorry that they are distancing themselves from me, but this is how it is. This distance kills everything. It [love] probably diminishes in time. I don't know if it's constant. I somehow think it diminishes in time. When I see them again, well it depends on their behaviours as well, but they are children so I try not to judge them. If they are also happy when they see me, even if for a little while? I don't know. Who knows? Probably they are feeling less and less happier.

This emotional reflexivity appears also in his relationship with his wife, not only in connection to his children:

I realize now, much later, that it's very important. I love my wife a lot, but I rarely told her that and in the end I guess she understood whatever she wanted and whatever she could. I realize verbalising things is important, because some people do not understand what you are feeling so you have to tell them exactly: 'Look I'm doing this thing because of this. I could've done it differently, but I didn't because of this and that'. I should've known this, but I didn't know where to learn it from. I've realized it afterwards.

Despite regret and disenchantment, Sergiu's love for his family members helps him resist the family separation through emotion $n$ work. He developed strategies for maintaining closeness to reconstruct a good fathering role on a new intimate basis. His narrative exemplifies what other sociologists have written concerning the links between culture and love. Arlie Hochschild suggested that "culture enters in as the medium in which human development, injury and repair take place" (p.5, 1998 in Bendelow). Lastly, in the wake of relationship breakdown people resort to culture to reconstruct their identity (Swidler, 2001). 


\section{Conclusion}

In this chapter I have represented interpersonal mobility in the intimate lives of two separated, non-resident and commuting European fathers from two different cultures, to illustrate points of emotional closeness and distance in how fathering happens in motion and can reshape identities. Sergiu and Keith's experiences of travelling for work between Scotland and Romania in the first case and between Scotland and England in the latter, as their romantic relationships dissolved, and their family life underwent changes, produced what I have called increased emotional reflexivity through 'travelling feelings'.

Sergiu's narrative was one of transforming his identity by adopting an intimate discourse in line with both 'good fathering' and 'caring masculinity'. The notion of 'good' in this context was equated with enhanced emotional expressiveness, even if underscored by a theme of emotional regret at experiencing the breakdown of his marriage. Keith's narrative follows the same path but one which according to him, a theme of emotional resentment appears as he became aware of shifting from the provider role to the intimate father. In this context, physical distance was also described in relation to a feeling that romantic love was experienced as 'slowly dying', which added to situations of permanent relationship-breakdown the disappointment of not living up to expectations of intimate involvement. However, this had to opposite effect for paternal love which could be strengthened and practiced more intensely.

In such cases father's emotion work was essential in bridging the spatial divide by maintaining the loving relationships with their children through various actions, either phoning them daily or moving permanently to be closer to them. These emotionally-inspired actions offered fathers the possibility to reinvent their roles and live up to new social expectations of intimate fathering. The travelling feelings that were borne out of these experiences were in the case of Keith, resentment and in the case of Sergiu, regret, they were brought to light using emotional reflexivity to make sense of their changing intimate lives. Both emotions have rather negative connotations but reflecting on them helped fathers re-assess their emotional connection to their children, and work at maintaining love.

In the case studies, paternal love was a verb, as father's emotional expression was connected to their masculinity; love in this context, took the form of an active demonstration, and as such it was tied in with a pattern of traditional masculinity which associates the accomplishment of maleness through action; this patter emerged from the accounts of all fathers included in the study, and was exemplified in this chapter in Keith and Sergiu's experiences. The examples they gave of love on the background of family separations, and as it developed from interactions and activities done with their children from a distance, pointed towards the socially-dependent character of this seemingly 'instinctive' emotion. In adopting the new role of the intimate father, both fathers were concerned with the level and visibility of their emotional involvement. This was brought to surface by their mutual situations of relationship breakdown and commuting for work to other cities. The dissolution of the intimate relationship between parents, or romantic love, is not an ultimate immovable end, but part of an active, ongoing project of 'doing family'. Families do not simply reside in given places, in static conditions, as uniform units. On the contrary, they form a complex and dynamic network of relationships that undergo periodic changes (related to both personal and structural flows, across time and geographical locations).

The themes emerging from the two case studies allude to the ways in which some academic men in long-distance relationships employed emotional reflexivity to keep in touch with their partners (Holmes, 2014). It also validates the view that social actors perform reflexive selves to maintain emotional connections (Illouz, 2012). In some of these situations it seems that geographical borders or obstacles in the ways of more embodied ways of relating, have the capacity not only to push some men to be more emotionally reflexive, but also to loosen father's emotional borders 
and determine them to become more engaged. In addition, such findings complement the emotional experiences of Chinese migratory fathers (Choi and Peng, 2016). One thing to note is that this is not at all a 'heroic' and always successful process (Kaufman, 2015), but it is based on consistent anxieties which must be emotionally managed.

Contemporary European families are constituted and maintained in time, across places and spaces by emotional and relational adjustments and negotiations, as family members adapt to the economic demands of work migration, commuting from city to city for work opportunities. Intimate lives are dynamic and marked by the personal transformations of each individual family member. Relational decisions such as divorce can disrupt one form of relationship (romantic love between parents) but also push other family members to adopt progressive forms of being, such as the shift from the provider to the intimate father's role. Endings as such can signal new beginnings as parental love is valued and maintained even across distances and social change is enacted in distinctly emotional ways.

\section{References:}

Beck, U., Beck-Gernsheim E. (2014) Distant Love: Personal life in the global age, Cambridge: Polity Press.

Bryceson, D.F, Vuorela, U. (2002) The Transnational Family: New European Frontiers and Global Networks, London: Bloomsbury Academic.

Burkitt, I. (2014) Emotions and social relations, London: Sage.

Bowlby, J. (1969) Attachment and loss - Vol. 1: Attachment, New York: Basic Books.

Choi, S.Y.P., Peng Y. (2016) Masculine compromise: migration, family, and gender in China, Oakland, California: University of California Press.

Dermott, E. (2008) Intimate fatherhood: a sociological analysis, London; New York: Routledge.

Ducu, V. (2018) Romanian Transnational Families: Gender, Family Practices and Difference, Basingstoke: Palgrave Macmillan.

Elliott, K. (2015) Caring Masculinities: Theorizing an Emerging Concept, Men and Masculinities, March (12): 240-259.

Fergusson, A, Jonasdottir, A.G. (2014) Love: A question for feminism in the 21st century, New York: Routledge/Taylor \& Francis Group .

Gallo, E., Scrinzi, F. (2016) Migration, Masculinities and Reproductive Labour: Men of the Home, Springer.

Haour-Knipe, M. (2001) Moving Families: Expatriation, Stress and Coping, Psychology Press.

Henwood, K., Procter, J. (2003) The 'good father': Reading men's accounts of paternal involvement during the transition to first-time fatherhood. British Journal of Social Psychology, Vol. $\underline{42(3)}, 337-355$.

Hochschild, A.R. (1998) The sociology of emotion as a way of seeing. In Bendelow G., Williams S.J. (1998) Emotions in social life: critical themes and contemporary issues. London: Routledge, pp.3-17.

Hochschild, A.R.., Machung, A. (1990) The Second Shift: Working parents and the revolution at home, Avon Books: New York.

Holmes, M. (2010) The Emotionalization of Reflexivity, Sociology, vol. 44(1), pp. 139-154. 
Holmes, M. (2014) Distance Relationships, Intimacy and Emotions amongst Academics and their Partners in Dual-Locations, Basingstoke: Palgrave Macmillan.

Hooks, b. (2004) The Will to Change: Men, Masculinity, and Love, Washington: Washington Square Press.

Illouz, E. (2012) Why love hurts : a sociological explanation, Cambridge, England; Polity Press.

Jamieson, L. (1998) Intimacy: Personal Relationships in Modern Societies, Cambridge: Polity Press.

Johansson, T., Andreasson, J. (2017) Fatherbood in Transition Masculinity, Identity and Everyday Life.

Kaufman, G. (2013) Superdads: How fathers balance work and care in the 21t century, New York: New York University Press.

Kilkey, M., Perrons, D., Plomien, A. (2013) Gender, Migration and Domestic Work: Masculinities: Male Labour and Fathering in the UK and USA, Springer.

Kilkey, M., Plomien, A. and Perrons, D. (2014) Migrant Men's Fathering Narratives, Practices and Projects in National and Transnational Spaces: Recent Polish Male Migrants to London. International Migration, 52: 178-191.

Kilkey, M., Palenga-Möllenbeck, E. (2016) Family Life in an Age of Migration and Mobility: Global Perspectives through the Life Course, Springer.

Kofman, E., Raghuram, P. (2015) Gendered Migrations and Global Social Reproduction, Springer

Lersch, P.M., Sergi V. (2014) Falling Out of Love and Down the Housing Ladder: A Longitudinal Analysis of Marital Separation and Home Ownership, European Sociological Review, 30(4): 512-524.

Morgan, D. H. J. (2011) Rethinking family practices, Basingstoke: Palgrave Macmillan.

Padilla, M.B., Hirsch, J.S., Munoz-Laboy, M., Sember, R.E., Parker, R.G. (Eds.) (2007) Love and Globalization: Transformations of Intimacy in the Contemporary World, Nashville: Vanderbilt University Press.

Reynolds, G., Letherby, G. (2012) Gendered Journeys, Mobile Emotions, Ashgate Publishing, Farnham: England.

Robila, M. (2009) Eastern European Immigrant Families, Abingdon, New York: Routledge.

Ralph, D. (2014) Work, Family and Commuting in Europe: The Lives of Euro-commuters, Basingstoke: Palgrave Macmillan.

Salazar-Parrenas, R. (2008) Transnational Fathering: Gendered Conflicts, Distant Disciplining and Emotional Gaps, Journal of Ethnic and Migration Studies, Vol. 34, (7), 1057-1072

Scheer, M. (2012) Are Emotions a Kind of Practice (and Is That What Makes Them Have a History)? A Bourdieuian Approach to Understanding Emotion. History and Theory, 51, 193-220.

Smart, C. (2007) Personal life: New directions in sociological thinking, Cambridge: Polity.

Souralová, A., Fialová, H. (2017) Where have all the fathers gone? Remarks on feminist research on transnational fatherhood, NORMA , 12(2): 159-174.

Swidler, A. (2001) Talk of Love: How Culture Matters. Chicago, Ill.; London: University of Chicago Press.

Turner, B., Stets, J. (2005) The sociology of emotions, Cambridge: Cambridge University Press. 
RUNNING HEADER: Families in Motion

Weber, M. (1978) Economy and Society: An Outline of Interpretive Sociology (trans. by Ephraim Fischoff), Berkeley, CA: University of California Press. 